\title{
REVIEW
}

\section{Cardiopulmonary assessment of patients with systemic sclerosis for hematopoietic stem cell transplantation: recommendations from the European Society for Blood and Marrow Transplantation Autoimmune Diseases Working Party and collaborating partners}

D Farge ${ }^{1,15}$, RK Burt ${ }^{2,15}$, M-C Oliveira ${ }^{3}$, E Mousseaux $^{4}$, M Rovira $^{5}$, Z Marjanovic ${ }^{6}, J_{\text {J de Vries-Bouwstra }}{ }^{7}$, N Del Papa $^{8}$, R Saccardi $^{9,16}$, SJ Shah ${ }^{10}$, DC Lee ${ }^{10}$, C Denton ${ }^{11}$, T Alexander ${ }^{12}$, DG Kiely ${ }^{13,18}$ and JA Snowden ${ }^{14,16,18}$ for the EBMT ADWP Scleroderma Working Group and on behalf of the Joint Accreditation Committee of the International Society for Cellular Therapy (JACIE) \& European Society for Blood and Marrow Transplantation (EBMT) ${ }^{17}$

Systemic sclerosis (SSc) is a rare disabling autoimmune disease with a similar mortality to many cancers. Two randomized controlled trials of autologous hematopoietic stem cell transplantation (AHSCT) for SSc have shown significant improvement in organ function, quality of life and long-term survival compared to standard therapy. However, transplant-related mortality (TRM) ranged from $3-10 \%$ in patients undergoing HSCT. In SSc, the main cause of non-transplant and TRM is cardiac related. We therefore updated the previously published guidelines for cardiac evaluation, which should be performed in dedicated centers with expertize in HSCT for SSc. The current recommendations are based on pre-transplant cardiopulmonary evaluations combining pulmonary function tests, echocardiography, cardiac magnetic resonance imaging and invasive hemodynamic testing, initiated at Northwestern University (Chicago) and subsequently discussed and endorsed within the EBMT ADWP in 2016.

Bone Marrow Transplantation (2017) 52, 1495-1503; doi:10.1038/bmt.2017.56; published online 22 May 2017

\section{INTRODUCTION}

Systemic sclerosis (SSc) is a rare and heterogeneous autoimmune disease of unknown origin, with an incidence of 1 in $100000 .^{1}$ It is characterized by skin and visceral (lung, gastrointestinal, cardiovascular and renal) fibrosis secondary to excessive collagen deposition with a limited cutaneous (Ic) and a diffuse cutaneous (dc) form. ${ }^{2}$ Rapidly progressive dc-SSc within the first 4 years of disease onset, observed in $10-20 \%$ of cases, is a life-threatening condition, with a 3-5 year survival between 50 and $70 \%,{ }^{3,4}$ the main cause of death being cardiac related., Numerous other factors have been reported to adversely reflect survival including extensive skin thickening (measured by the modified Rodnan skin score), ${ }^{7}$ altered functional status (measured using the Self Health
Assessment Questionnaire), altered renal function (presence of either hypertension, proteinuria, urinary casts having excluded non-SSc specific causes) or lung involvement (reflected in abnormal lung function or CT appearances) and older age at onset. $^{8-11}$ Recently, more sensitive cardiac evaluations indicate that some of these adverse prognostic factors may be associated with markers of cardiac involvement. Pulmonary arterial hypertension (PAH) and pulmonary fibrosis ${ }^{12,13}$ are also common causes of death. While hypoxemic respiratory failure may occur, the penultimate cause of death from $\mathrm{PAH}$ or interstitial lung disease (ILD) is often not suffocation per se, that is, inability to oxygenate blood, but rather cardiac failure in many patients.

Standard therapy with daily oral or monthly intravenous cyclophosphamide regimens in SSC has demonstrated only

\footnotetext{
${ }^{1}$ Department of Internal Medicine, Unité Clinique de Médecine Interne, Maladies Auto-immunes et Pathologie Vasculaire, UF 04, Hôpital Saint-Louis, AP-HP Assistance Publique des Hôpitaux de Paris, INSERM UMRS 1160, Paris Denis Diderot University, Paris, France; ${ }^{2}$ Department of Medicine, Division of Immunotherapy, Northwestern University, Chicago, IL, USA; ${ }^{3}$ Departamento de Clínica Médica, Center for Cell-based Therapy, Regional Blood Center of Ribeirão Preto, Ribeirão Preto Medical School, University of São Paulo, Ribeirão Preto, Brazil; ${ }^{4}$ Hôpital Européen Georges Pompidou, AP-HP Assistance Publique des Hôpitaux de Paris, INSERM UMR 970, Université Paris Descartes, Paris, France; ${ }^{5}$ Department of Hematology, HSCT Unit, Hospital Clinic, Barcelona, Spain; ${ }^{6}$ Department of Hematology, Saint-Antoine Hospital Paris, Assistance Publique des Hôpitaux de Paris, APHP, Paris, France; ${ }^{7}$ Leiden University Medical Center, Leiden, The Netherlands; ${ }^{8}$ Department of Rheumatology, Scleroderma Clinic, Osp. G. Pini, Milan, Italy; ${ }^{9}$ Department of Hematology, Cord Blood Bank, Careggi University Hospital, Florence, Italy; ${ }^{10}$ Division of Cardiology, Northwestern University Feinberg School of Medicine, Chicago, IL, USA; ${ }^{11}$ UCL Division of Medicine Royal Free Campus, London, UK; ${ }^{12}$ Department of Rheumatology and Clinical Immunology, Charité University Medicine Berlin, Berlin, Germany; ${ }^{13}$ Sheffield Pulmonary Vascular Disease Unit, M-floor, Royal Hallamshire Hospital, Sheffield, UK and ${ }^{14}$ Department of Haematology, Sheffield Teaching Hospitals NHS Foundation Trust, University of

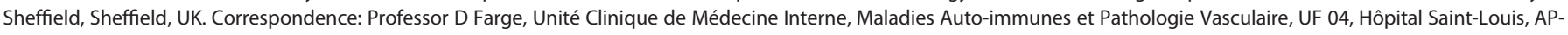
HP Assistance Publique des Hôpitaux de Paris, INSERM UMRS 1160, Paris Denis Diderot University, Paris 75010, France.
}

E-mail: dominique.farge-bancel@aphp.fr

${ }^{15}$ These authors contributed equally to this work.

${ }^{16}$ Affiliated to JACIE and EBMT.

${ }^{17}$ The members of EBMT ADWP Scleroderma Working Group members and EULAR contributors has been listed before references.

${ }^{18}$ These authors contributed equally to this work as senior authors.

Received 9 January 2017; accepted 29 January 2017; published online 22 May 2017 
limited benefit. ${ }^{14,15}$ In contrast, early phase II trials ${ }^{16,17}$ and the randomized controlled ASSIST ${ }^{18}$ followed by the large European ASTIS phase III trials in $\mathrm{SSC}^{19}$ have shown that AHSCT using a high-dose cyclophosphamide regimen significantly improved forced vital capacity, decreased diseased-lung volume, and that SSc ILD might be partially reversed with continued improvement in lung function for at least 2 years after transplantation. ${ }^{18-20}$ The presence of extensive lung disease or of specific cardiac involvement in patients undergoing AHSCT is associated with an increased transplant-related mortality (TRM), reflecting concerns that cardiac impairment or impaired respiratory function may directly or indirectly compromise cardiac function ${ }^{21}$ and translate into high TRM due to inability to cope with complications. Due to direct cardiotoxicity of drugs, transplant-related fever, neutropenic infection and to saline overload during AHSCT, an extensive cardiac evaluation to exclude $\mathrm{PAH}$ and primary or secondary SSc-related cardiac involvement and constrictive pericarditis is essential to reduce the risk of $\mathrm{TRM}^{22}$ and to provide an acceptable risk-benefit ratio of $\mathrm{AHSCT}^{21}$

The aim of these guidelines is to summarize the current evidence-based practices and to make recommendations as to how TRM from AHSCT may be minimized through multiprofessional collaboration, careful patient selection, optimized treatment regimens and audit of outcomes. This cardiopulmonary guidelines process was initiated to update previous consensus ${ }^{23}$ after 10 years of additional international experience, as initiated at Northwestern University (Chicago) ${ }^{21}$ and subsequently discussed and endorsed within the European Society for Blood and Marrow Transplantation (EBMT)-Autoimmune Disease Working Party (ADWP) in 2016.

\section{CARDIOPULMONARY INVOLVEMENT IN SYSTEMIC SCLEROSIS}

\section{Cardiac complications}

In early stages of disease, cardiac impairment is clinically underappreciated and often overlooked by standard echocardiographic reporting of gross wall motion abnormalities and left ventricular ejection fraction (LVEF). ${ }^{24}$ Relying on LVEF alone can be misleading, since SSc hearts may have a restrictive or constrictive physiology with relatively intact LVEF, but significant diastolic dysfunction. ${ }^{22,25,26}$ As the disease may be clinically silent for a long time, clinical studies only report a $10-61 \%$ prevalence of cardiac involvement by using transthoracic echocardiography (TTE) as a screening tool, ${ }^{5,27}$ while it ranges between 50 and $81 \%$ in autopsybased studies of SSc. ${ }^{28,29}$ In the EUSTAR database concerning 7073 patients, ${ }^{26}$ LVEF was estimated by TTE using Simpson's method and the prevalence of $\mathrm{LVEF}<55 \%$ was $5.4 \%$. In contrast, a high prevalence of reduced left ventricle (LV) and/or right ventricle (RV) contractility in SSc patients despite a normal LVEF was detected when more sophisticated tools were used, such as tissue Doppler or cardiac magnetic resonance (CMR) imaging.

Ferri et al. ${ }^{8}$ reported $36 \%$ of SSc deaths related to cardiac disease alone, and a recent literature search, ${ }^{6}$ comprising a total of 12829 SSc patients from 18 cohort studies, found that causes of death were $19.7 \%$ cardiac and $13.1 \%$ pulmonary hypertension, and the risk of death was increased in patients with cardiac involvement (hazard ratio (HR) 3.15)) and with PAH (HR 3.50). In daily clinical practice, cardiac evaluation of SSc patients is based on the results from clinical examination, electrocardiography (ECG) and TTE, and in the presence of palpitations or abnormalities on ECG, on $24 \mathrm{~h}$ Holter monitoring. B-type natriuretic peptide (BNP) or N-terminal pro-BNP can be elevated as a marker of myocardial stress usually reflecting the presence of right heart failure or $\mathrm{PAH} .^{30}$
Pulmonary artery hypertension

Pulmonary hypertension $(\mathrm{PH})$ is defined at right heart catheterization (RHC) as a mean pulmonary artery pressure $(\mathrm{mPAP}) \geqslant 25 \mathrm{mmHg}$. The current system of classification identifies five major groups, which define treatment and prognosis. ${ }^{31,32} \mathrm{PAH}$ is a rare form of pulmonary hypertension due to a vasculopathy. $\mathrm{PAH}$ complicating SSC has a poor prognosis significantly worse than idiopathic $\mathrm{PAH}^{32,33}$ and requires specific vascular endothelium-targeted therapy. However, given the high prevalence of co-existing cardiac and lung disease, $\mathrm{PH}$ is also commonly seen in SSC in the presence of pulmonary hypertension-left heart disease (PH-LHD) and interstitial lung disease (PH-lung), where treatment of pulmonary hypertension should be directed at the underlying SSc-related heart or lung disease. Distinguishing these forms of pulmonary hypertension can be challenging in SSc, however, it is important not only in defining treatment but also survival. Indeed, patients with SSC and $\mathrm{PH}$-lung have a worse prognosis than other PAH patients ${ }^{33,34}$ while SSc patients with $\mathrm{PH}-$ LD appear to have a significantly better prognosis. ${ }^{32}$ A large metaanalysis ${ }^{35}$ from a number of registries identified a 1-year survival of $81 \%$ and 3 -year survival of $52 \%$ in patients with SSC and $\mathrm{PAH}$. Depending on the method used to diagnose $\mathrm{PAH}$, its prevalence varies widely. However, using RHC as the gold standard, a metaanalysis has calculated a prevalence of PAH in SSC of $9 \%{ }^{36}$

Screening for PAH in SSc with echocardiography is advocated by the European Society of Cardiology and European Respiratory Societies (ESC/ERS), who use tricuspid regurgitation velocity jet to decide on the need for further investigation. ${ }^{37}$ However, a single threshold at echocardiography cannot be used to confidently exclude $\mathrm{PAH}$, because tricuspid regurgitation velocity is not always present and/or can be eccentric leading to lower tricuspid regurgitation velocity, and in some studies comparing $\mathrm{RHC}$ to Doppler, tricuspid regurgitation velocity did not accurately reflect invasive pressures. ${ }^{38}$ We and others have described the inaccuracies of echocardiographic systolic arterial pressure estimation. ${ }^{39,40}$ Furthermore, in the absence of lung disease, a significantly reduced free diffusion of carbon monoxide (DLCO) had high specificity, but no threshold could be used to confidently exclude $\mathrm{PAH}{ }^{41}$ Consequently, a complex scoring system, DETECT has been advocated as a screening tool for $\mathrm{PAH}$ in $\mathrm{SSc}^{38}$ and this study reports a much higher sensitivity than echocardiography alone. The DETECT algorithm missed $4 \%$ of PAH patients (false negatives), but recommended $\mathrm{RHC}$ in $62 \%$ of patients while the strategy following 2009 ESC/ERS guidelines ${ }^{37}$ missed $29 \%$ of diagnoses, and required a $\mathrm{RHC}$ referral rate of $40 \%$. A limitation of the DETECT study is that this algorithm was only validated for patients with a SSc diagnosis of $>3$ years and a DLCO $<60 \%$. Therefore, it is likely that the value of the proposed algorithm is less accurate for those SSc patients with early rapidly progressive SSc within $<4$ years after onset of diagnosis, who are the best candidates for AHSCT.

There is also increasing interest in the outcome of patients with SSc who do not by strict criteria have pulmonary hypertension, but have mPAP measured at basal RHC in the range $(21-24 \mathrm{mmHg})$. Two studies identified that between 31 and 55\% of these patients went on to develop resting $\mathrm{PAH}$ with a significant proportion doing so within 1 year of follow-up. ${ }^{42,43}$ These borderline patients will require careful assessment to exclude left heart disease. If transplanted, careful follow-up in prospective registries is important to ensure that they do not have a high medium-term mortality risk related to the early development of PAH. Given these uncertainties, there should be a low threshold for performing $\mathrm{RHC}$ in SSC patients considered for AHSCT. Performance of RHC appears a sensible mandatory requirement to exclude or confirm $\mathrm{PAH}$ in SSc patients considered for AHSCT, since when using the current cyclophosphamide intense transplant regimens, $\mathrm{PAH}$ is a contraindication to $\mathrm{AHSCT}^{21,44}$ 


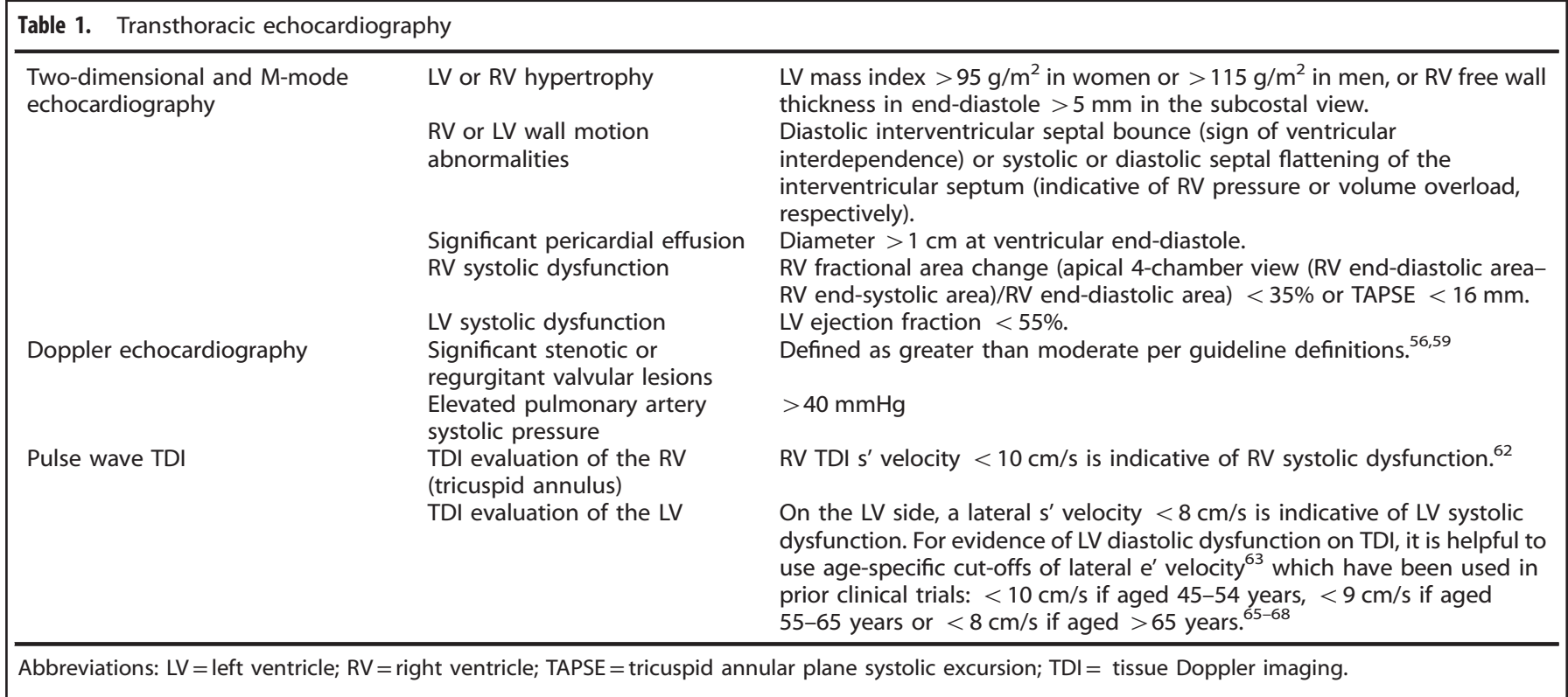

Interstitial lung disease

ILD is common in SSc patients and almost a uniform finding at post mortem. ${ }^{45}$ It ranges from a relatively limited and slowly progressive condition seen most frequently in limited cutaneousSSc to a more florid, rapidly progressive form seen more commonly dc-SSc. High resolution (HR) computed tomography has revolutionized the identification and clinical assessment of ILD and is more sensitive than chest radiograph. ${ }^{46} \mathrm{~A}$ number of highresolution computed tomography patterns correlate with histological changes: including: (i) non-specific interstitial pneumonia, which is the most commonly observed and characterized by a mixture of ground glass change and fine reticular abnormalities often extending sub-pleural to the medulla, (ii) usual interstitial pneumonitis, characterized by sub-pleural reticular changes with irregular linear opacities and cyst formation/honeycombing with no or minimal ground glass change (iii) organizing pneumonia, usually bilateral and consisting of areas of consolidation/nodular change. Assessing the severity of lung disease to define clinical course and help in decisions regarding the risk-benefit ratio of AHSCT can be challenging. Detailed assessment using volume CT to evaluate the extent of lung disease plus lung function testing is required to exclude patients at higher risk of TRM, but also importantly to gain prospective data on potential treatment benefits.

\section{HOW TO ASSESS CARDIOPULMONARY INVOLVEMENT IN SSC PATIENTS BEFORE REFERRAL FOR TRANSPLANT}

Transthoracic echocardiography

Although TTE, as routinely performed in SSc patient follow-up is not without limitations, it provides important information (Table 1).

Two-dimensional and M-mode echocardiographic findings that should be investigated include (1) significant LV or RV hypertrophy, (2) overt RV or LV wall motion abnormalities (including diastolic interventricular septal bounce), (3) significant pericardial effusion, (4) RV systolic dysfunction and (5) LV systolic dysfunction. Important Doppler findings on TTE that must be evaluated further in SSC prior to AHSCT include the following: (1) any hemodynamically significant stenotic or regurgitant valvular lesions, (2) elevated systolic arterial pressure, (3) notching in the RV outflow tract pulse Doppler tracing, a sign of pulmonary hypertension ${ }^{47}$ or (4) moderate or greater LV diastolic dysfunction for the diagnosis and grading of LV diastolic dysfunction. ${ }^{48}$

Pulse wave tissue Doppler imaging of the lateral (anterior) tricuspid annulus and septal and lateral mitral annulus should be performed on all SSc patients undergoing evaluation for HSCT. Tissue Doppler imaging evaluation of the RV (tricuspid annulus) and LV (lateral mitral annulus) can provide important clues to the diagnosis of RV and LV dysfunction, respectively.

Speckle-tracking echocardiography, a method for quantitating myocardial mechanics that can detect subtle abnormalities in myocyte calcium cycling and myocardial fibrosis, ${ }^{49}$ is also an important tool for analyzing subclinical myocardial dysfunction in $\mathrm{SSc}^{50}$ It remains to be seen whether speckle-tracking indices such as global longitudinal strain and early diastolic strain rate of both the LV and RV will be helpful beyond the other, more routine testing (TTE, CMR and invasive hemodynamic testing with fluid challenge) that we currently recommend for pre-AHSCT evaluation in the SSc patient.

\section{Cardiac magnetic resonance imaging}

CMR has emerged as the gold standard to assess right and left ventricular systolic function (LVSF), myocardial fibrosis and pericardial disease. It provides important complementary information not necessarily detected by TTE. ${ }^{51}$ In a consecutive series of SSc patients, TTE detected abnormalities in only $45 \%$ when CMR observed abnormalities in $75 \%$ of cases. ${ }^{51}$ In fact, in patients with SSc, ECG, CMR and RHC without and with a fluid challenge provide independent assessments of cardiac response to stress and are all required to adequately assess pre-AHSCT risk.

Ventricular morphology and function. Cine CMR is considered the gold standard technique for quantifying ventricular mass, volumes and function (Figures $1 \mathrm{a}$ and $\mathrm{b}$ ). Without the need for contrast, the high blood-myocardial signal difference improves endocardial border definition resulting in superior inter-study reproducibility for left ventricular volumes, function and mass when compared to ECG. $^{52}$ In 50 SSc patients free of cardiac symptoms, CMR detected lower RV ejection fraction compared with controls, and lower RV EF in dc-SSc compared with Ic-SSc suggesting a role for CMR in identifying subclinical RV dysfunction in SSc patients. ${ }^{53}$ Cine CMR is the best method to detect diastolic flattening of the interventricular septum 'D-sign', an indicator of either right- 

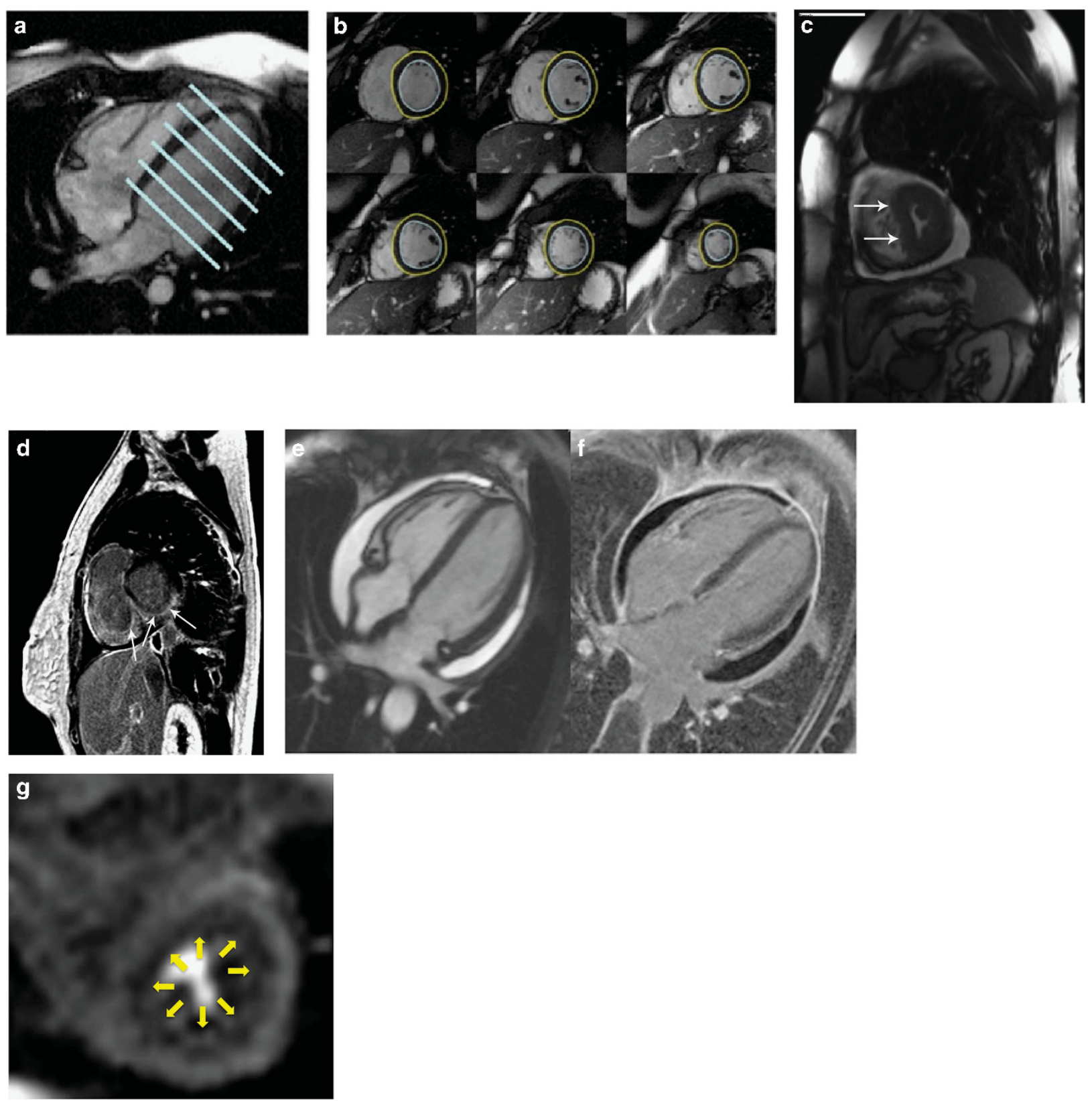

Figure 1. (a, b) Cine CMR: A four chamber view (left) with positions of each slice of a short axis stack (right). Imaging is performed in the 2chamber, 3-chamber and 4-chamber long axis views and in a stack of short axis slices, typically acquired every $10 \mathrm{~mm}$ from the mitral valve plane to the apex. Mass and volume are quantified from the short axis stack according to Simpson's Rule by slice summation, which avoids making any geometric assumptions about the shape of the ventricle. The high blood-myocardial contrast and ability to quantify volumes without geometric assumptions is especially useful in the RV, because of its complex shape, abundant trabeculations and thin wall. Because gadolinium contrast agents are confined to the extracellular space, the change in T1 relaxation time is inversely related to the contrast agent volume of distribution. Even without the administration of contrast, native T1 mapping detects prolongation of T1 in SSc. Active inflammation can be assessed by T2-weighted images, which demonstrate increased signal in areas of myocardial edema. Abnormal myocardial T2 signal has been described in patients with SSc. ${ }^{50}$ Endocardial (blue) and epicardial (yellow) borders are drawn, enabling calculation of left ventricular mass and chamber volume according to Simpson's rule. ${ }^{55}$ (c) Diastolic flattening of interventricular septum, 'D-sign', visualized by cine CMR. Adapted from Burt et al. ${ }^{22} \mathrm{http}: / /$ www.jrheum.org/content/39/2/206.long, reproduced with permission from Journal of Rheumatology and Richard Burt. (d) Focal fibrosis in a SSc patient involving the mid and epicardial myocardium, sparing the subendocardium, as visualized by LGE-CMR. Because gadolinium contrast agents are confined to the extracellular space, the change in T1 relaxation time is inversely related to the contrast agent volume of distribution. CMR measurement of the relative gadolinium concentration in the blood and myocardium, and the direct measurement of the volume of distribution of gadolinium in the blood (1-hematocrit), enables calculation of extracellular volume fraction (ECV), an index of the volume of distribution of contrast agent in the myocardium. Adapted from Burt et al. ${ }^{22} \mathrm{http} / / / \mathrm{www} . \mathrm{jrheum} . \mathrm{org} /$ content/39/2/206.long, ${ }^{20}$ reproduced with permission from Journal of Rheumatology and Richard Burt. (e, $\mathbf{f}$ ) Pericardial effusion seen as bright white on Cine CMR (left) and dark black on phase sensitive inversion recovery LGE-CMR (right). Pericardial thickening and enhancement are also seen on LGE-CMR. (g) Global subendocardial hypoperfusion in a SSc patient seen on adenosine stress CMR perfusion imaging. 
Table 2. RHC with fluid challenge

RA pressure tracing

PA pressure waveform

Fluid challenge during $\mathrm{RHC}$
Kussmaul's sign: abnormal rise in RA pressure during inspiration, reflective of an inability of the RV to handle increased blood volume, which can be due to a non-compliant RV, a non-compliant pericardium (that is, constrictive pericarditis) or significant (typically severe) tricuspid regurgitation.

On the RV pressure tracing, a dip-and-plateau sign is indicative of either a non-compliant RV or constrictive pericarditis. As is the case with the RA pressure tracing, a tall A wave at end-diastole in the RV pressure tracing is a sign of a non-compliant RV.

A wide PA pulse pressure (PA systolic pressure-PA diastolic pressure) is a sign of increased PA stiffness.

$\mathrm{PH}$ is defined as a mean PA pressure $\geqslant 25 \mathrm{mmHg}$, while PAH is defined as a mean PA pressure $\geqslant 25 \mathrm{mmHg}$ and pulmonary arterial wedge pressure (PAWP) $<15 \mathrm{mmHg}$ (along with elevated pulmonary vascular resistance [PVR] $>3.0$ Wood units). In patients with pulmonary venous hypertension (i.e., PH with PAWP $\geqslant 15 \mathrm{mmHg}$ ), an elevated diastolic pulmonary gradient (PA diastolic pressure - PCWP) $>7 \mathrm{mmHg}$ is a sign of combined post-capillary and pre-capillary. If RA pressure is $\leqslant 12 \mathrm{mmHg}$ and PAWP $\leqslant 20 \mathrm{mmHg}$ at rest, we recommend intravenous fluid challenge with $10 \mathrm{cc} / \mathrm{kg}$ warmed normal saline, infused over a 10-min period. The RA, PA and PAWP pressure should be measured, along with the cardiac output, immediately after the fluid challenge. Signs that demonstrate inability of the SSc patient to handle a volume load include:

(1) RA pressure post $>$ PCWP post or $\triangle \mathrm{RA}$ pressure $>\triangle \mathrm{PCWP}$, which are signs of RV dysfunction.

(2) Increased mean PA pressure post $>35 \mathrm{mmHg}$, increased PVR post $>3$ Wood units or increased DPG post $>7 \mathrm{mmHg}$, which are indicative of stiff pulmonary vasculature.

(3) Increased PAWP post $>25 \mathrm{mmHg}$, which is indicative of LV diastolic dysfunction.

(4) Unchanged or decreased cardiac output post, which is indicative of RV or LV dysfunction.

(5) Exaggerated dip-and-plateau pattern in the RV pressure tracing, which is a sign of restrictive or constrictive physiology.

Abbreviations: $\mathrm{DPG}=$ diastolic pulmonary vascular pressure gradient; $\mathrm{LV}=$ left ventricle; $\mathrm{PA}=$ pulmonary artery; $\mathrm{PAWP}=$ pulmonary arterial wedge pressure $\mathrm{PCWP}=$ pulmonary capillary wedge pressure; $\mathrm{PVR}=$ pulmonary vascular resistance; $\mathrm{RA}=$ right atrial; $\mathrm{RHC}=$ right heart catheterization; $\mathrm{RV}=$ right ventricle; $\mathrm{SSC}=$ systemic sclerosis.

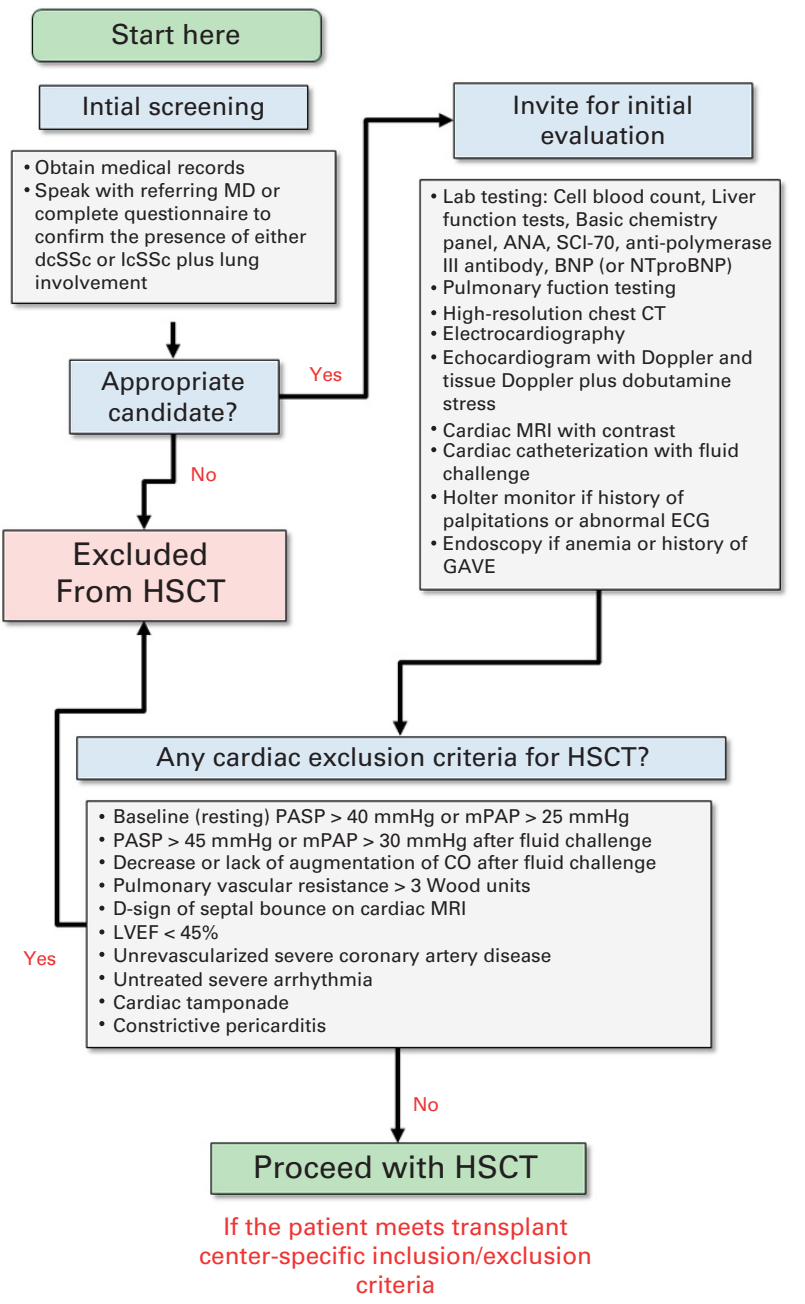

Figure 2. Flowchart for baseline evaluations and SSc patient selection criteria prior to AHSCT. sided volume or pressure overload and elevated pulmonary vascular resistance or in the absence of $\mathrm{PH}$ and of RV systolic dysfunction with a constrictive and/or restrictive physiology (Figure 1c).

Myocardial tissue characterization. Late gadolinium-enhanced CMR (LGE-CMR) can accurately identify the presence, location, size and morphology of irreversibly damaged myocardium. Regions of focal myocardial fibrosis become enhanced relative to healthy myocardium several minutes after administration of a gadolinium-based contrast agent (Figure 1d). In the chronic setting, fibrotic tissue has a larger interstitial space than normal myocardium leading to a higher regional concentration of extracellular contrast agent, more $\mathrm{T} 1$ shortening and brighter signal. In SSc patients, focal myocardial fibrosis may result from recurrent vasospasm, ischemia-reperfusion injury and inflammation. Focal myocardial fibrosis is frequently seen in SSc patients by LGE-CMR (14\% to $66 \%) .^{51,56-58}$ In SSC autopsy studies, the majority of myocardial fibrosis was evident only on microscopic examination. ${ }^{59}$ This type of diffuse fibrosis may be underestimated or even missed by LGE-CMR, which relies on differential contrast uptake between diseased and normal myocardium. Newer techniques employing T1 mapping now enable quantification of diffuse myocardial fibrosis by calculating the myocardial extracellular volume fraction. ${ }^{60}$

Pericardial disease is common in SSc and can include pericardial effusion, pericarditis, cardiac tamponade and constrictive pericarditis. Pericardial effusions are well seen both on cine and LGE imaging (Figures 1e and f). Increased ventricular interdependence is manifested as a 'septal bounce'-early diastolic flattening or inversion of the interventricular septum seen during inspiration followed by a right-sided septal shift during exhalation seen on free breathing cine CMR.

Myocardial perfusion. SSc is often complicated by microvascular coronary artery disease, which manifests as diffuse limitation in vasodilator reserve. CMR first-pass perfusion imaging has a higher spatial resolution, and can detect subendocardial perfusion defects that are below the resolution afforded by single-photon 
Table 3. Baselines evaluation and SSC patient selection prior to HSCT according to ADWP consensus

Suggested baseline evaluations History

Standard hematological, biological and urinary analyses and viral serologies Immunology according to EBMT/EULAR Consensus Core Set

Cardiopulmonary

Gastrointestinal For patients with history of GAVE or anemia or iron deficiency, endoscopy should be performed and vascular

Complete history and examination including evaluation of quality of life by SHAQ-VAS, and/ or SF-36 questionnaires and of the extent of skin thickening by the mRSS.

Blood cell count, ESR.

Chemistry: electrolytes, renal and liver function tests, proteins, CK, BNP or NT-proBNP, troponin T or troponin I, CRP. Urine: protein/creatinine ratio; urine analysis, casts.

Viral serologies: CMV, HSV, VZV, EBV, VDRL, HIV, (HTLV-1,2), Hepatitis B and C and autoantibody titers.

ANA, anti-Scl-70, anti-centromere and anti-polymerase RNA III antibodies (indicates high risk for renal crisis).

Immune-phenotyping by FACS of peripheral blood mononuclear cells $=\mathrm{CD}^{+}, \mathrm{CD}^{+}, \mathrm{CD}^{+}, \mathrm{CD}^{+} \mathrm{CD} 45 \mathrm{RA}, \mathrm{CD} 4^{+}$ CD45RO, CD31, CD3 ${ }^{-} \mathrm{CD}_{6} 6^{+} \mathrm{CD} 16^{+}, \mathrm{CD} 19^{+}, \mathrm{CD} 14^{+}$; $\operatorname{lgG}$, IgA, IgM).

Biobanking: storage of plasma, serum, RNA, DNA.

Chest X-ray, and exercise test (6MWT) is recommended.

ECG with rhythm strip, $24 \mathrm{~h}$ Holter monitoring in clinically symptomatic patients (for example, palpitations, dizziness) or in those with rhythm abnormality on 12-lead ECG or rhythm strip.

Comprehensive TTE with Doppler and tissue Doppler imaging.

CMR with contrast and deep breathing cine images to evaluate for interventricular septal flattening or bounce. Invasive RHC including a fluid challenge.

Contiguous and High resolution thoracic CT (or multi slice CT-scan with 6 HR section slices).

Pulmonary function studies (including TLC, VC, DLCO, DLCO/VA, RV). ectasia, even if not actively bleeding, should undergo cauterization repeated on two or three occasions several weeks later to prevent massive bleeding during transplant induced thrombocytopenia.

Suggested exclusion criteria for AHSCT in SSC using a cyclophosphamide-based regimen.

Age

Pregnancy Pregnancy or unwillingness to use adequate contraception throughout investigation.

Psychiatric

Consent

Psychiatric disease including alcohol or drug abuse.

Inability to provide informed consent for treatment.

Liver function

Twofold increase in liver transaminases or bilirubin.

Failure of synthetic function or evidence of cirrhosis.

Neoplasms

Infection

Neoplasms myelodysplasia or serious hematological disorders contraindicating AHSCT.

Heart

LVEF $<45 \%$

mPAP $>25 \mathrm{mmHg}$ or PASP $>40 \mathrm{mmHg}$ without fluid challenge.

mPAP $>30 \mathrm{mmHg}$ or PASP $>45 \mathrm{mmHg}$ with $1000 \mathrm{cc}$ NS infused over $10 \mathrm{~min}$.

Diastolic septal flattening (D-sign).

Septal bounce.

Constrictive pericarditis.

Cardiac tamponade.

Significant atherosclerotic disease.

Arrhythmias that cannot be pharmacologically controlled, cardioverted or ablated.

Pulmonary FVC $<65 \%$

DLCO-SB $<40 \%$.

Note: if pre-HSCT echocardiogram, CMR, and cardiac catheterization with and without fluid challenge demonstrate no contraindication, patients with lower DLCO and FVC may be considered candidates.

Patients should be strongly encouraged to stop smoking.

Renal

Glomerular filtration rate $<40 \mathrm{~mL} / \mathrm{min} / 1.73 \mathrm{~m}^{2}$

Note: patients with renal crises or renal failure may be considered candidates if blood pressure is well controlled and dialysis is performed the morning following each cyclophophamide infusion, respectively.

Abbreviations: $6 \mathrm{MWT}=6$ minutes walking test; $\mathrm{ADWP}=$ Autoimmune Disease Working Party; $\mathrm{AHSCT}=$ autologous hematopoietic stem cell transplantation; $\mathrm{BNP}=\mathrm{B}$-type natriuretic peptide; $\mathrm{CMR}=$ cardiac magnetic resonance; $\mathrm{CT}=$ computerized tomography; $\mathrm{DLCO}=$ diffusion of $\mathrm{CO}$; $\mathrm{DLCO} / \mathrm{NA}=\mathrm{KCO}$ carbon monoxide transfer coefficient; $E C G=$ electrocardiography; $E S R=$ erythrocyte sedimentation rate; $F V C=$ forced vital capacity; $H R=$ high resolution; $\mathrm{HTLV}=$ human T-lymphotropic virus; LVEF = left ventricular ejection fraction; $\mathrm{mPAP}=$ mean pulmonary artery pressure; $\mathrm{mRSS}=$ modified Rodnan skin score; $\mathrm{NT}$-proBNP = N-terminal pro-BNP; RV= residual volume; $\mathrm{SSC}=$ systemic sclerosis; $\mathrm{TLC}=$ total lung capacity; $\mathrm{VA}=$ alveolar volume; $\mathrm{VC}=$ vital capacity; $\mathrm{VDRL}=$ venereal disease research laboratory test.

emission CT (SPECT; Figure 1g). In SSC patients treated with nifedipine, the upslope ratio of CMR perfusion time-intensity curves in the myocardium and blood (a semi-quantitative index of myocardial perfusion) increased from baseline after 14 days of treatment. Because the diffuse microvascular coronary artery disease seen in SSc results in global reduction in myocardial perfusion, quantification of perfusion ${ }^{61}$ may provide advantages over visual assessment and analysis techniques that rely on relative perfusion differences between adjacent segments.
Diastolic dysfunction. Advancements in CMR velocity encoding techniques now allow accurate measurement of blood and myocardial velocities. Emerging techniques enabling quantification of myocardial perfusion, myocardial diffuse fibrosis and diastolic dysfunction are likely to further enhance the utility of CMR in the evaluation of SSC patients for AHSCT.

Right heart catheterization with fluid challenge

RHC is considered the gold standard test for the diagnosis of $\mathrm{PAH}^{62}$ and is an essential part of the diagnostic work-up for both 
Table 4. AHSCT procedures according to EBMT and international consensus

Mobilization and Leukapheresis

Conditioning and peripheral stem cell infusion

Supportive care
PBSCs may be mobilized using either cyclophosphamide $2 \mathrm{~g} / \mathrm{m}^{2}$ infused in one session or $4 \mathrm{~g} / \mathrm{m}^{2}$ divided equally over 2 consecutive days followed by G-CSF $5-10 \mu \mathrm{g} / \mathrm{kg} /$ day and leukapheresis according to institutional protocols. A minimum of $3.0 \times 10^{6} / \mathrm{kg} \mathrm{CD} 34^{+}$at harvest and freeze resulting in minimum $2.0 \times 10^{6} / \mathrm{kg}$ viable CD34 ${ }^{+}$cells is required for transplant. Conditioning should not be initiated until at least 3-4 weeks of mobilization cyclophosphamide dose to minimize accumulated acute cyclophosphamide myocardial injury. Prior to conditioning a central venous catheter will be placed.

The current published conditioning regimen consists of cyclophosphamide $50 \mathrm{mg} / \mathrm{kg} /$ day intravenously for 4 consecutive days (total $200 \mathrm{mg} / \mathrm{kg}$ ) and rbATG (thymoglobulin) at total doses of $6.5-7.5 \mathrm{mg} / \mathrm{kg}$, delivered according to institutional protocols.

Given the potential of ATG-induced fever to destabilize patients, intravenous methylprednisolone $>3-10 \mathrm{mg} / \mathrm{kg}$ will be given to improve tolerability of the rbATG and decrease fever. ATG fever is also minimized by limiting the first dose of ATG to not more than $0.5 \mathrm{mg} / \mathrm{kg}$.

The interval between the last dose of cyclophosphamide and infusion of the graft should be at least $48 \mathrm{~h}$.

On day 0 stem cells are thawed and infused according to local standard operating procedures.

The minimum number of $\mathrm{CD} 34^{+}$cells reinfused should be $2 \times 10^{6} / \mathrm{kg}$, whether the graft is unselected or CD34 ${ }^{+}$selected. Supportive care measures, including prophylactic or therapeutic antibiotics, anti-viral, anti-pneumocystis and anti-fungal agents, will be taken according to local standard operating procedures for such patients. Adherence to specific guidelines is recommended (according to EBMT standards).

Transfusions will be given in accordance with local standard operating procedures for such patients. Based on current transplantation-experiences in scleroderma patients, particular attention should be paid to thrombocytopenia, bleeding tendency, hypo and hypertension, and respiratory insufficiency.

For both mobilization and conditioning, cyclophosphamide should be given with appropriate hydration and mesna (to prevent hemorrhagic cystitis), but extreme care must be taken in fluid balance management as patients are sensitive to overload.

Abbreviations: AHSCT = autologous hematopoietic stem cell transplantation; EBMT = European Society for Blood and Marrow Transplantation; rbATG $=$ rabbit antithymocyte globulin.

$\mathrm{PAH}$ and constrictive pericarditis. ${ }^{63}$ Given the inability to reliably exclude $\mathrm{PAH}$ using non-invasive techniques, all SSc patients should undergo RHC during evaluation for AHSCT (Table 2), and the test should be performed and interpreted by operators experienced in hemodynamic testing. It is important to ensure proper zeroing of the pressure transducer, and all pressures should be measured at end-expiration (at which time intrathoracic pressure is closest to zero).

On the right atrial (RA) pressure tracing, evidence of increased RV stiffness includes a prominent A wave (reflecting increased resistance to atrial contraction due to a non-compliant RV) and increased RA pressure during inspiration (Kussmaul's sign). Prominent $\mathrm{V}$ waves on the RA pressure tracing indicate significant tricuspid regurgitation. If any of these signs is present on the RA pressure tracing, the pre-transplant SSc patient should be further evaluated to determine whether there is significant RV fibrosis, primary RV failure, constrictive pericarditis or tricuspid regurgitation.

It is also helpful to analyze the PA pressure waveform on invasive hemodynamic testing (Table 2). Evidence of PAH or combined postand pre-capillary PAH on RHC testing are absolute contraindications for AHSCT in SSc. Patients with mild isolated pulmonary venous hypertension can undergo diuresis with re-evaluation, although these patients will be susceptible to adverse effects from fluid overload during AHSCT and should therefore be carefully evaluated to exclude significant LV systolic or diastolic dysfunction.

Fluid challenge during $\mathrm{RHC}$ is an important part of the preAHSCT evaluation in SSC as a method for understanding the cardiopulmonary response to increased volume. Although $\mathrm{RHC}$ is considered to be a gold standard for hemodynamic assessment, it only provides a snapshot of the patient at rest, and typically occurs after fasting for $>8 \mathrm{~h}$. Since AHSCT involves the administration of a considerable volume load, fluid challenge can be very helpful to examine the response of the cardiopulmonary system to increased volume in patients with SSc, and should be performed in all patients in whom resting RA pressure $<12 \mathrm{mmHg}$ and pulmonary capillary wedge pressure (PCWP) $<20 \mathrm{mmHg}$. An exaggerated rise in RA pressure, mean PA pressure or PCWP, the emergence of a dip-and-plateau sign on RV pressure tracing, and/or lack of augmentation of cardiac output are all potential signs of a compromised SSc heart or pulmonary vasculature in need of further assessment and could signify the need to exclude patients from AHSCT. ${ }^{20,21}$

\section{SSC PATIENT SELECTION CRITERIA AND PROCEDURES FOR AUTOLOGOUS HEMATOPOIETIC STEM CELL TRANSPLANTATION}

Referral criteria

Generally, patients should be considered for AHSCT if their age is under 65 and onset of SSc within 5 years, although patients with disease of up to 10 years duration have been transplanted without increased risk, provided pre-cardiac assessment was normal. Best candidates for AHSCT are patients within the first 4 years of rapidly progressive dc-SSc onset and a life-threatening condition with a 3-5 year survival, as well established by recent meta-analysis ${ }^{3}$ and large EUSTAR prospective ${ }^{4}$ studies. Until more cardiac-safe noncyclophosphamide intensive regimens are developed, only patients without evidence for $\mathrm{PAH}$ and sufficient cardiopulmonary function based on defined selection criteria (Figure 2, Table 3) are eligible for AHSCT.

\section{Procedures of AHSCT}

In October 2016, more than 2200 patients with autoimmune diseases treated by AHSCT have been reported to the EBMT database, including 440 patients with SSc, while 136 patients with SSc have been transplanted in Chicago. AHSCT procedures (mobilization, leukapheresis, conditioning, peripheral stem cell infusion, supportive and post-transplant care) are detailed in Table 4. Each center will follow its own local protocol for AHSCT with regard to the risk/benefit balance after careful standard clinical and biological patient pre-transplant evaluation, whereas the local treatment regimen and follow-up evaluation will be recorded and analyzed according to ADPW guidelines. ${ }^{44,64}$

\section{CONCLUSIONS}

Recently published evidence in randomized controlled trials has shown significant improvement in organ function, quality of life, disability and long-term survival. However, because of vital organ 
damage caused by SSc, the risks of transplant-related complications and treatment-related mortality risks have been relatively high compared with other diseases. There is a need for more thorough screening and evaluation of patients, as described herein, to decrease the risk of transplant toxicity within specialized centers of SSc-related transplant expertise.

\section{CONFLICT OF INTEREST}

The authors declare no conflict of interest.

\section{ACKNOWLEDGEMENTS}

We acknowledge the JACIE Committee and Manuela Badoglio (ADWP EBMT study coordinator) for her help in preparing the manuscript. EBMT ADWP Scleroderma Working Group members and EULAR contributors Tobias Alexander, Renate Arnold, Manuela Badoglio (ADWP data manager), Thomas Daikeler, Nicoletta Del Papa, Christopher P Denton, Dominique Farge, Jörg Henes, David G Kiely, Zora Marjanovic, Thierry Martin, John Moore, Elie Mousseaux, Maria Carolina Oliveira, Montserrat Rovira, Riccardo Saccardi, Hans Ulrich Scherer, Belinda Simoes, John A Snowden, Jeska de Vries-Bouwstra.

\section{AUTHOR CONTRIBUTIONS}

DF and RKB contributed equally to this article as first authors and DGK and JS contributed equally as senior authors. Concept and design: DF, RS, TA and JAS. Drafting of the manuscript: DF, RKB, DGK, EM and JAS. Critical revision of the manuscript for important intellectual content: DF, RKB, MCO, EM, MR, ZM, JdVB, $\mathrm{RS}, \mathrm{SJS}, \mathrm{DCL}, \mathrm{CD}, \mathrm{TA}, \mathrm{DGK}$ and JAS. The current recommendations are based on pre-transplant cardiac evaluations first initiated at Northwestern University (RKB, SJS and DCL), Chicago and subsequently discussed at the EBMT ADWP Meetings held in Sheffield (November 2013) Paris (November 2014) and Istanbul (March 2015).

\section{EBMT ADWP SCLERODERMA WORKING GROUP MEMBERS AND EULAR CONTRIBUTORS}

Renate Arnold, Manuela Badoglio (ADWP data manager), Thomas Daikeler, Jörg Henes, Thierry Martin, John Moore, Montserrat Rovira, Hans Ulrich Scherer, Belinda Simoes.

\section{REFERENCES}

1 Gabrielli A, Avvedimento EV, Krieg T. Scleroderma. N Engl J Med 2009; 360: 1989-2003.

2 van den Hoogen F, Khanna D, Fransen J, Johnson SR, Baron M, Tyndall A et al. 2013 classification criteria for systemic sclerosis: an American College of Rheumatology/European League against Rheumatism collaborative initiative. Ann Rheum Dis 2013; 72: 1747-1755.

3 loannidis JPA, Vlachoyiannopoulos PG, Haidich A-B, Medsger TA Jr, Lucas M, Michet $\mathrm{CJ}$ et al. Mortality in systemic sclerosis: an international meta-analysis of individual patient data. Am J Med 2005; 118: 2-10.

4 Fransen J, Popa-Diaconu D, Hesselstrand R, Carreira P, Valentini G, Beretta L et al. Clinical prediction of 5-year survival in systemic sclerosis: validation of a simple prognostic model in EUSTAR centres. Ann Rheum Dis 2011; 70: 1788-1792.

5 Desai CS, Lee DC, Shah SJ. Systemic sclerosis and the heart: current diagnosis and management. Curr Opin Rheumatol 2011; 23: 545-554.

6 Elhai M, Meune C, Avouac J, Kahan A, Allanore Y. Trends in mortality in patients with systemic sclerosis over 40 years: a systematic review and meta-analysis of cohort studies. Rheumatology 2012; 51: 1017-1026.

7 Clements P, Lachenbruch P, Siebold J, White B, Weiner S, Martin R et al. Inter and intraobserver variability of total skin thickness score (modified Rodnan TSS) in systemic sclerosis. J Rheumatol 1995; 22: 1281-1285.

8 Ferri C, Valentini G, Cozzi F, Sebastiani M, Michelassi C, La Montagna G et al. Systemic sclerosis: demographic, clinical, and serologic features and survival in 1012 Italian patients. Medicine 2002; 81: 139-153.

9 Scussel-Lonzetti L, Joyal F, Raynauld J-P, Roussin A, Rich E, Goulet J-R et al. Predicting mortality in systemic sclerosis: analysis of a cohort of 309 French Canadian patients with emphasis on features at diagnosis as predictive factors for survival. Medicine 2002; 81: 154-167.
10 Domsic RT, Rodriguez-Reyna T, Lucas M, Fertig N, Medsger TA Jr. Skin thickness progression rate: a predictor of mortality and early internal organ involvement in diffuse scleroderma. Ann Rheum Dis 2011; 70: 104-109.

11 Tyndall AJ, Bannert B, Vonk M, Airò P, Cozzi F, Carreira PE et al. Causes and risk factors for death in systemic sclerosis: a study from the EULAR Scleroderma Trials and Research (EUSTAR) database. Ann Rheum Dis 2010; 69: 1809-1815.

12 Chung L, Domsic RT, Lingala B, Alkassab F, Bolster M, Csuka ME et al. Survival and predictors of mortality in systemic sclerosis-associated pulmonary arterial hypertension: outcomes from the pulmonary hypertension assessment and recognition of outcomes in scleroderma registry. Arthritis Care Res 2014; 66: 489-495.

13 Hachulla E, Clerson P, Airò P, Cuomo G, Allanore Y, Caramaschi P et al. Value of systolic pulmonary arterial pressure as a prognostic factor of death in the systemic sclerosis EUSTAR population. Rheumatology 2015; 54: 1262-1269.

14 Nannini C, West CP, Erwin PJ, Matteson EL. Effects of cyclophosphamide on pulmonary function in patients with scleroderma and interstitial lung disease: a systematic review and meta-analysis of randomized controlled trials and observational prospective cohort studies. Arthritis Res Ther 2008; 10: R124.

15 Tashkin DP, Elashoff R, Clements PJ, Roth MD, Furst DE, Silver RM et al. Effects of 1-year treatment with cyclophosphamide on outcomes at 2 years in scleroderma lung disease. Am J Respir Crit Care Med 2007; 176: 1026-1034.

16 Farge D, Labopin M, Tyndall A, Fassas A, Mancardi GL, Van Laar J et al. Autologous hematopoietic stem cell transplantation for autoimmune diseases: an observational study on 12 years' experience from the European Group for Blood and Marrow Transplantation Working Party on Autoimmune Diseases. Haematologica 2010; 95: 284-292.

17 Oliveira MC, Labopin M, Henes J, Moore J, Papa ND, Cras A et al. Does ex vivo $\mathrm{CD}_{4}{ }^{+}$positive selection influence outcome after autologous hematopoietic stem cell transplantation in systemic sclerosis patients?. Bone Marrow Transplant 2015; 51: 501-505.

18 Burt RK, Shah SJ, Dill K, Grant T, Gheorghiade M, Schroeder J et al. Autologous non-myeloablative haemopoietic stem-cell transplantation compared with pulse cyclophosphamide once per month for systemic sclerosis (ASSIST): an open-label, randomised phase 2 trial. Lancet 2011; 378: 498-506.

19 van Laar JM, Farge D, Sont JK, Naraghi K, Marjanovic Z, Larghero J et al. Autologous hematopoietic stem cell transplantation vs intravenous pulse cyclophosphamide in diffuse cutaneous systemic sclerosis: a randomized clinical trial. JAMA 2014; 311: 2490-2498.

20 Launay D, Marjanovic Z, de Bazelaire C, Florea L, Zohar S, Keshtmand H et al. Autologous hematopoietic stem cell transplant in systemic sclerosis: quantitative high resolution computed tomography of the chest scoring. J Rheumatol 2009; 36: 1460-1463.

21 Burt RK, Oliveira MC, Shah SJ, Moraes DA, Simoes B, Gheorghiade M et al. Cardiac involvement and treatment-related mortality after non-myeloablative haemopoietic stem-cell transplantation with unselected autologous peripheral blood for patients with systemic sclerosis: a retrospective analysis. Lancet 2013; 381: 1116-1124.

22 Burt RK, Shah SJ, Gheorghiade M, Ruderman E, Schroeder J. Hematopoietic stem cell transplantation for systemic sclerosis: if you are confused, remember: 'it is a matter of the heart'. J Rheumatol 2012; 39: 206-209.

23 Saccardi R, Tyndall A, Coghlan G, Denton C, Edan G, Emdin M et al. Consensus statement concerning cardiotoxicity occurring during haematopoietic stem cell transplantation in the treatment of autoimmune diseases, with special reference to systemic sclerosis and multiple sclerosis. Bone Marrow Transplant 2004; 34: 877-881.

24 Meune C, Avouac J, Wahbi K, Cabanes L, Wipff J, Mouthon L et al. Cardiac involvement in systemic sclerosis assessed by tissue-doppler echocardiography during routine care: a controlled study of 100 consecutive patients. Arthritis Rheum 2008; 58: 1803-1809.

25 Meune C, Vignaux O, Kahan A, Allanore Y. Heart involvement in systemic sclerosis: evolving concept and diagnostic methodologies. Arch Cardiovasc Dis 2010; 103: 46-52.

26 Allanore Y, Meune C, Vonk MC, Airo P, Hachulla E, Caramaschi P et al. Prevalence and factors associated with left ventricular dysfunction in the EULAR Scleroderma Trial and Research group (EUSTAR) database of patients with systemic sclerosis. Ann Rheum Dis 2010; 69: 218-221.

27 de Groote P, Gressin V, Hachulla E, Carpentier P, Guillevin L, Kahan A et al. Evaluation of cardiac abnormalities by Doppler echocardiography in a large nationwide multicentric cohort of patients with systemic sclerosis. Ann Rheum Dis 2008; 67: 31-36.

28 Sandmeier B, Jäger VK, Nagy G, Carreira PE, Tzankov A, Widuchowska M et al. Autopsy versus clinical findings in patients with systemic sclerosis in a case series from patients of the EUSTAR database. Clin Exp Rheumatol 2015; 33: S75-S79.

29 Jacobsen S, Halberg P, Ullman S. Mortality and causes of death of 344 Danish patients with systemic sclerosis (scleroderma). Br J Rheumatol 1998; 37: 750-755. 
30 Williams MH, Handler CE, Akram R, Smith CJ, Das C, Smee J et al. Role of $\mathrm{N}$-terminal brain natriuretic peptide (N-TproBNP) in scleroderma-associated pulmonary arterial hypertension. Eur Heart J 2006; 27: 1485-1494.

31 Kiely DG, Elliot CA, Sabroe I, Condliffe R. Pulmonary hypertension: diagnosis and management. Brit Med J 2013; 346: f2028.

32 Hurdman J, Condliffe R, Elliot CA, Davies C, Hill C, Wild JM et al. ASPIRE registry: assessing the Spectrum of Pulmonary hypertension Identified at a REferral centre. Eur Respir J 2012; 39: 945-955.

33 Condliffe R, Kiely DG, Peacock AJ, Corris PA, Gibbs JSR, Vrapi F et al. Connective tissue disease-associated pulmonary arterial hypertension in the modern treatment era. Am J Respir Crit Care Med 2009; 179: 151-157.

34 Mathai SC, Hummers LK, Champion HC, Wigley FM, Zaiman A, Hassoun PM et al. Survival in pulmonary hypertension associated with the scleroderma spectrum of diseases: impact of interstitial lung disease. Arthritis Rheum 2009; 60: 569-577.

35 Lefèvre G, Dauchet L, Hachulla E, Montani D, Sobanski V, Lambert M et al. Survival and prognostic factors in systemic sclerosis-associated pulmonary hypertension: a systematic review and meta-analysis. Arthritis Rheum 2013; 65: 2412-2423.

36 Avouac J, Airò P, Meune C, Beretta L, Dieude P, Caramaschi P et al. Prevalence of pulmonary hypertension in systemic sclerosis in European Caucasians and metaanalysis of 5 studies. J Rheumatol 2010; 37: 2290-2298.

37 Galiè N, Humbert M, Vachiery J-L, Gibbs S, Lang I, Torbicki A et al. 2015 ESC/ERS Guidelines for the diagnosis and treatment of pulmonary hypertension: the joint task force for the diagnosis and treatment of pulmonary hypertension of the European Society of Cardiology (ESC) and the European Respiratory Society (ERS): endorsed by: Association for European Paediatric and Congenital Cardiology (AEPC), International Society for Heart and Lung Transplantation (ISHLT). Eur Heart J 2016; 37: 67-119.

38 Coghlan JG, Denton CP, Grünig E, Bonderman D, Distler O, Khanna D et al. Evidence-based detection of pulmonary arterial hypertension in systemic sclerosis: the DETECT study. Ann Rheum Dis 2014; 73: 1340-1349.

39 Rich JD, Shah SJ, Swamy RS, Kamp A, Rich S. Inaccuracy of Doppler echocardiographic estimates of pulmonary artery pressures in patients with pulmonary hypertension: implications for clinical practice. Chest 2011; 139: 988-993.

40 Fisher MR, Forfia PR, Chamera E, Housten-Harris T, Champion HC, Girgis RE et al. Accuracy of Doppler echocardiography in the hemodynamic assessment of pulmonary hypertension. Am J Respir Crit Care Med 2009; 179: 615-621.

41 Mukerjee D St, George D, Knight C, Davar J, Wells AU, Du Bois RM et al. Echocardiography and pulmonary function as screening tests for pulmonary arterial hypertension in systemic sclerosis. Rheumatology 2004; 43: 461-466.

42 Valerio CJ, Schreiber BE, Handler CE, Denton CP, Coghlan JG. Borderline mean pulmonary artery pressure in patients with systemic sclerosis: transpulmonary gradient predicts risk of developing pulmonary hypertension. Arthritis Rheum 2013; 65: 1074-1084.

43 Bae S, Saggar R, Bolster MB, Chung L, Csuka ME, Derk C et al. Baseline characteristics and follow-up in patients with normal haemodynamics versus borderline mean pulmonary arterial pressure in systemic sclerosis: results from the PHAROS registry. Ann Rheum Dis 2012; 71: 1335-1342.

44 Snowden JA, Saccardi R, Allez M, Ardizzone S, Arnold R, Cervera R et al. Haematopoietic SCT in severe autoimmune diseases: updated guidelines of the European Group for Blood and Marrow Transplantation. Bone Marrow Transplant 2012; 47: 770-790.

45 D'Angelo WA, Fries JF, Masi AT, Shulman LE. Pathologic observations in systemic sclerosis (scleroderma). A study of fifty-eight autopsy cases and fifty-eight matched controls. Am J Med 1969; 46: 428-440.

46 Walsh SLF, Sverzellati N, Devaraj A, Keir GJ, Wells AU, Hansell DM. Connective tissue disease related fibrotic lung disease: high resolution computed tomographic and pulmonary function indices as prognostic determinants. Thorax 2014; 69: 216-222.

47 Arkles JS, Opotowsky AR, Ojeda J, Rogers F, Liu T, Prassana V et al. Shape of the right ventricular Doppler envelope predicts hemodynamics and right heart function in pulmonary hypertension. Am J Respir Crit Care Med 2011; 183: 268-276.

48 Plana JC, Galderisi M, Barac A, Ewer MS, Ky B, Scherrer-Crosbie M et al. Expert consensus for multimodality imaging evaluation of adult patients during and after cancer therapy: a report from the American Society of Echocardiography and the European Association of Cardiovascular Imaging Eur Heart J Cardiovasc Imaging 2014; 15: 1063-1093.

49 Shah SJ, Aistrup GL, Gupta DK, O'Toole MJ, Nahhas AF, Schuster D et al. Ultrastructural and cellular basis for the development of abnormal myocardial mechanics during the transition from hypertension to heart failure. Am J Physiol Heart Circ Physiol 2014; 306: H88-100.

50 Yiu KH, Schouffoer AA, Marsan NA, Ninaber MK, Stolk J, Vlieland TV et al. Left ventricular dysfunction assessed by speckle-tracking strain analysis in patients with systemic sclerosis: relationship to functional capacity and ventricular arrhythmias. Arthritis Rheum 2011; 63: 3969-3978.
51 Hachulla A-L, Launay D, Gaxotte V, de Groote P, Lamblin N, Devos P et al. Cardiac magnetic resonance imaging in systemic sclerosis: a cross-sectional observational study of 52 patients. Ann Rheum Dis 2009; 68: 1878-1884.

52 Grothues F, Smith GC, Moon JCC, Bellenger NG, Collins P, Klein HU et al. Comparison of interstudy reproducibility of cardiovascular magnetic resonance with two-dimensional echocardiography in normal subjects and in patients with heart failure or left ventricular hypertrophy. Am J Cardiol 2002; 90: 29-34.

53 Bezante GP, Rollando D, Sessarego M, Panico N, Setti M, Filaci G et al. Cardiac magnetic resonance imaging detects subclinical right ventricular impairment in systemic sclerosis. J Rheumatol 2007; 34: 2431-2437.

54 Henein $M$, Lindqvist $P$, Francis D, Mörner S, Waldenström A, Kazzam E. Tissue Doppler analysis of age-dependency in diastolic ventricular behaviour and filling: a cross-sectional study of healthy hearts (the Umeå General Population Heart Study). Eur Heart J 2002; 23: 162-171.

55 Lee DC, Caroll TC. Magnetic resonance imaging. In: Goldberger JJ, Ng J (eds). Practical Signal and Image Processing in Clinical Cardiology. Springer: New York, NY, USA, 2010, pp 251-274.

56 Mavrogeni S, Bratis K, van Wijk K, Stavropoulos E, Hautemann D, Reiber JHC et al. Myocardial perfusion-fibrosis pattern in systemic sclerosis assessed by cardiac magnetic resonance. Int J Cardiol 2012; 159: e56-e58.

57 Tzelepis GE, Kelekis NL, Plastiras SC, Mitseas P, Economopoulos N, Kampolis C et al. Pattern and distribution of myocardial fibrosis in systemic sclerosis: a delayed enhanced magnetic resonance imaging study. Arthritis Rheum 2007; 56: 3827-3836.

58 Di Cesare E, Battisti S, Di Sibio A, Cipriani P, Giacomelli R, Liakouli V et al. Early assessment of sub-clinical cardiac involvement in systemic sclerosis (SSc) using delayed enhancement cardiac magnetic resonance (CE-MRI). Eur J Radiol 2013; 82: e268-e273.

59 Bulkley BH, Ridolfi RL, Salyer WR, Hutchins GM. Myocardial lesions of progressive systemic sclerosis. A cause of cardiac dysfunction. Circulation 1976; 53: 483-490.

60 Ntusi NAB, Piechnik SK, Francis JM, Ferreira VM, Rai ABS, Matthews PM et al. Subclinical myocardial inflammation and diffuse fibrosis are common in systemic sclerosis--a clinical study using myocardial T1-mapping and extracellular volume quantification. J Cardiovasc Magn Reson 2014; 16: 21.

61 Lee DC, Johnson NP. Quantification of absolute myocardial blood flow by magnetic resonance perfusion imaging. JACC Cardiovasc Imaging 2009; 2: 761-770.

62 Shah SJ. Pulmonary hypertension. JAMA 2012; 308: 1366-1374.

63 Nishimura RA. Constrictive pericarditis in the modern era: a diagnostic dilemma. Heart 2001; 86: 619-623.

64 Alexander T, Bondanza A, Muraro PA, Greco R, Saccardi R, Daikeler T et al. SCT for severe autoimmune diseases: consensus guidelines of the European Society for Blood and Marrow Transplantation for immune monitoring and biobanking. Bone Marrow Transplant 2015; 50: 173-180.

65 Baumgartner H, Hung J, Bermejo J, Chambers JB, Evangelista A, Griffin BP et al. Echocardiographic assessment of valve stenosis: EAE/ASE recommendations for clinical practice. J Am Soc Echocardiogr 2009; 22: 1-23-102.

66 Zoghbi WA, Enriquez-Sarano M, Foster E, Grayburn PA, Kraft CD, Levine RA et al. Recommendations for evaluation of the severity of native valvular regurgitation with two-dimensional and Doppler echocardiography. J Am Soc Echocardiogr 2003; 16: 777-802.

67 Rudski LG, Lai WW, Afilalo J, Hua L, Handschumacher MD, Chandrasekaran K et al. Guidelines for the echocardiographic assessment of the right heart in adults: a report from the American Society of Echocardiography endorsed by the European Association of Echocardiography, a registered branch of the European Society of Cardiology, and the Canadian Society of Echocardiography. J Am Soc Echocardiogr 2010; 23: 685-713 788 .

68 Solomon SD, Janardhanan R, Verma A, Bourgoun M, Daley WL, Purkayastha D et al. Effect of angiotensin receptor blockade and antihypertensive drugs on diastolic function in patients with hypertension and diastolic dysfunction: a randomised trial. Lancet 2007; 369: 2079-2087.

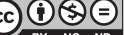

This work is licensed under a Creative Commons AttributionNonCommercial-NoDerivs 4.0 International License. The images or other third party material in this article are included in the article's Creative Commons license, unless indicated otherwise in the credit line; if the material is not included under the Creative Commons license, users will need to obtain permission from the license holder to reproduce the material. To view a copy of this license, visit http:// creativecommons.org/licenses/by-nc-nd/4.0/

(c) The Author(s) 2017 